\title{
Dynamic Assessment in Language Learning; An Overview and the Impact of Using Social Media
}

\author{
Haya Mohammed Anazi Alsaadi ${ }^{1,2}$ \\ ${ }^{1}$ Department of English, Faculty of languages and translation, King Khalid University, Abha, Saudi Arabia \\ ${ }^{2}$ Department of English, College of Arts, University of Bisha, Bisha, Saudi Arabia \\ Correspondence: Haya Mohammed Anazi Alsaadi, Department of English, Faculty of languages and translation, \\ King Khalid University, Abha, Saudi Arabia \& Department of English, College of Arts, University of Bisha, \\ Bisha, Saudi Arabia.
}

Received: June 23, 2021

Accepted: July 26, 2021

Online Published: July 29, 2021

doi: $10.5539 /$ elt.v14n8p73

URL: https://doi.org/10.5539/elt.v14n8p73

\begin{abstract}
Language assessment is a vital part of the process of learning and teaching a foreign language. Language learners need to be provided with the best methods to measure how much they are acquiring the target language and to select the most authentic tasks of testing for them. As it has been recommended to use multiple assessment instead of traditional summative one where nothing is concerned except measurement of decontextualized tasks without interactive feedback, dynamic assessment has been used as a means to reinforce learning and to motivate students as well as enhance language teaching. Dynamic assessment, can be rooted on Socio-cultural theory (SCT) and Zone of Proximal Development (ZPD) by Vygotsky, as it allows for learning through interaction and mediation which indicates how beneficial it could be to utilize this method of assessment particularly through social media which is embedded nowadays with all of our daily tasks. Thus, this paper demonstrates the nature and effects of dynamic assessment as an influential method of assessing and maintaining the progress of language learners. Additionally, a comparison between dynamic assessment and static one is manifested. Besides, the theoretical background that supports this method is displayed. Moreover, how technology has been used effectively in language assessment and testing is illustrated. Furthermore, this paper presents implications and recommendations for further research regarding using social media to implement dynamic assessment in language learning which is considered the major goal of reviewing this literature.
\end{abstract}

Keywords: Dynamic assessment (DA), mediation, MALL, social media, static assessment, Zone of Proximal Development (ZPD)

\section{Introduction}

Assessment is one of the most demanding aspects in education to be considered. Additionally, it is an essential part of any learning process as Gipps (1994) has demonstrated the possible goals of assessing the students in the educational courses that it supports teaching and learning, provides information about learners, teachers and schools, and acts as a selection and certificating device, as an accountability procedure. Moreover, successful ways of assessment can lead to radical improvements in the curriculum and teaching methodologies. In the dynamic process of foreign language learning and teaching as a crucial educational field of study, language assessment and testing can be described as an indispensable part. Therefore, it has been a fertile domain of studying and researching in the progress of language learning.

The traditional form of assessment has been used as an activity to recognize the learners' current level of knowledge about language or their ability to use the language. It measures how much students have obtained of what they have already learned in their courses which has been described by researchers as "static assessment". This way of assessing can be considered a frustrating and isolated method of evaluating learners' progress. Indeed, it is a distorted approach to deal with particularly in language assessment (Nazari, 2014). To modify such ways of assessing language learners, dynamic assessment has been adopted as a highly beneficial approach which can contribute extremely in enhancing language learning and teaching. It is considered one of the recent approaches that increasingly being used by educationalists around the world and is broadly seen as a valuable way. The core idea of dynamic assessment (DA) is grounded in the term created by the Russian psychologist Lev Vygotsky (1980) in his social interactionalist approach, Zone of Proximal Development (ZPD). Dynamic 
assessment is concerned with measuring language learners' performance through their interaction with a teacher or a more experienced peer.

\section{Dynamic Assessment}

\subsection{What is Dynamic Assessment}

Dynamic assessment is considered one of the recent approaches of assessing the progress of language learners. Dynamic Assessment is a method of conducting a language assessment to determine the abilities that an individual possesses as well as their learning potential. It is increasingly being used by educational psychologists around the world and is broadly seen as a valuable way. It is often referred to as an active measuring technique for the learner's perception, thinking, understanding, and problem-solving abilities (Hasson, 2017). This approach focuses primarily on the learning process while also taking into account the amount and type of examiner investment. Moreover, it has also been noted as being highly interactive and process-oriented. Indeed, it is highly beneficial to be used for assessing learners from a variety of cultural and linguistic backgrounds. To explain, it can be stated that dynamic assessment is noted to affect learners by modifying their cognitive functioning as well as bridging the gap between traditional testing and cultural-linguistic evaluation. Poehner and Lantolf (2005) have clarified the goal of dynamic assessment that it is not only to assist learners to get through a specific task but also to help them to succeed with their future tasks through the negotiation that is presented by teachers.

Dynamic assessment (DA) is usually defined as an approach which integrates both teaching and assessment activities simultaneously. To illustrate, DA pictures instruction and assessment as two sides of the same coin that are not separable in sense that good instruction involves assessment and good assessment involves instruction (Tabatabaei \& Bakhtiarvand, 2014). Thus, instruction and assessment are two complimentary aspects of methodology which should optimally result in true learning. Furthermore, other studies have identified the assessment method as a test-teach retest model because it emphasizes a person's ability to learn skills and knowledge that are conceived the test by a specific instruction (Lauchlan \& Carrigan, 2013). Additionally, Lantolf and Poehner (2004) have described dynamic assessment as an approach that integrates assessment with instruction to build up learner's development through appropriate forms of mediation. Dynamic Assessment procedure involves a structured process of mapping tasks by the use of unknown objects to signify pretense during a play in order to enable the learner to identify the intended word and apply it during the conversation (Hasson, 2017). Indeed, dynamic assessment can be described as it is closer to a situation of instruction rather than examination.

To display the procedures of dynamic assessment that occur between teachers and students, Lussier and Swanson (2005) have stated that dynamic assessment as a "procedure that attempts to modify performance, via examiners' assistance, in an effort to understand learning potential"(p. 66). Furthermore, Beak and Kim (2003) have declared that DA requires the interaction between teachers and students. When a student has difficulty in solving a problem or answering a question, the teacher attempts to guide the student to create paths by modifying the format, providing additional examples or trials, modeling an appropriate strategy for answers, or offering increasingly more direct cues or prompts. Beak and Kim (2003) have presented dynamic assessment procedures in a highly concrete form by explaining the sequential steps that can take place to create dynamic assessment. First, the examiner tests the learner working alone (static mode) to provide a measurement of skills on a task to establish a baseline. Second, the examiner provides a controlled protocol of assistance and instruction (dynamic mode) while the child works on a comparable task. Third, a post-test is given with an alternate form of the original measurement while the learner works alone (static mode) on the task. Fourth, the examiner compares the test and retest measurements to establish the learners' zone of proximal development. Fifth, the examiner analyzes the learner's performance on both product and process. However, this form can be assumed to be complicated compared to the various forms of dynamic assessment during classes that teachers simply can practice to measure their students' comprehension and performance.

Since the process of dynamic assessment involves a form of an active teaching and learning by perception, observation, and thinking; it can be possible to modify the cognitive functions of the learner as well as change the problem-solving patterns to accommodate with individual differences of learners. Studies conducted to determine factors resulting to low-performance level among learners have revealed that there is no correlation between their performance, learning potential, and social backgrounds. According to these studies, many learners fail in static tests due to a lack of opportunities for learning experiences, cultural differences, special learning difficulties, or traumatic life experiences (Rashidi et al., 2018). Therefore, dynamic assessment has been recommended to be used in psychoanalysis and counseling fields (Cornfield, 2001; Falik, 2000; Haywood \& 
Lidz, 2007). Additionally, it has been utilized in neuropsychology, which is the evaluation of cultural differences and cognitive programs (Haywood \& Tzuriel, 2013).

\subsection{The Effects of Dynamic Assessment on Language Learners}

To investigate the radical effects of dynamic assessment on foreign language learners, numerous issues need to be considered. It is important to note that this method of assessment has been shown to have a number of effects on learners, despite the fact that dynamic assessment does not produce a score like commercially available tests, it portrays the actual development status of the learner as the evaluator observes the learner and is capable of judging if the learner is developing or is disordered as well as quantify the degree or severity of the disorder. The typical performance of the learners is easy to determine as the evaluator can assess the learner within the same speech community and draw a conclusion based on the observation made by the evaluator (Pena et al., 2014).

It can be assured that dynamic assessment is a great method of measurement that can help a lot to deal with even complex cases of learners. This is particularly true for people who have mental or motivational issues that interfere with their cognitive abilities. Dynamic Assessment is intended to provide accurate information about: (a) relevant cognitive factors (such as impulsivity and planning behavior) that affect problem-solving ability and academic failure and success; and (b) an individual's current learning ability and learning processes); (c) motivational, emotional, and personality factors that affect cognitive processes; and (d) effective teaching strategies for the child being investigated (Lauchlan \& Carrigan, 2013). Moreover, diversified research on dynamic assessment in second language context focuses on the classroom and the interaction between learner and mediator, and finally how this interaction functions to understand and improve learner's proficiency (Lantolf \& Poehner, 2011). As it has been stated by Rashidi and Nejad (2018) in their study that investigates the effects of dynamic assessment on the EFL learners writing development, that the ultimate goals of dynamic assessment are for promoting development and providing learners' motivation. They have found in their study that learners made remarkable improvement as a result of the mediations that have been made based on the most salient concept of ZPD, developed by Vygotsky. These mediations have been manifested through the interaction between teachers and learners by language tools such as dialogues and discussions. Besides, Ableeva (2010) has conducted a study on the effects of DA on improving listening comprehension of students learning French as a foreign language. It has been found that DA clarifies the sources of learners' poor performance that were unknown during traditional assessments and indicates not only the actual level of learners' listening ability but also their potential level of development while simultaneously enhancing this development. Additionally, Compernolle and Williams (2012) have delved into the effect of DA on developing a conceptual understanding of sociocultural features of variation in French for some pronouns. Their study has evidenced that DA could help the learners to grow a more profound insight into such features. In the same vein, van Compernolle and Williams (2012) have proved that students make progress within their ZPD due to their dialogic discussion on the sociocultural level of the classroom even if they are not directly addressed by the teacher that the students who were not directly addressed by the teacher. Thus, dynamic assessment is a beneficial means to reinforce learning and to motivate students as well as an effective device to assess their performance in the language.

\subsection{Dynamic Assessment vs Non-Dynamic Assessment}

To compare dynamic assessment with the traditional methods of measuring the performance and abilities of learners, several studies have been conducted and fruitful findings have been generalized. It has to be stated that assessment and instruction are typically described as distinct activities, existing in a dichotomous relationship according to traditional assessment. Assessment is seen as an activity not only distinct, but even at odds with the goals of teaching which is completely contradicts the view in dynamic assessment. Furthermore, assessment has been used in the form of artificial problems or questions. Thus, it results detached from the concrete context students are in (Cacchione, 2015). Unlike static assessment method which can be described as passive, standardized, and observational; dynamic assessment involves active participation for both learners and examiner. It can be apparently described as modifiable and responsive. Dynamic Assessment process indeed is completely different from static assessment. To embark on this, it involves the examiner not only to present a test and identify the errors during the learning session but also to use this outcome to determine the learners' deficiencies and strengths. However, static tests are not recommended to have an impact on the learners' progress in a number of ways which they include evaluating only the learner's ability to display a set of behaviors and using the outcome to determine a specific level of performance.

The static assessment methods have also been noted to be very problematic as they operate on assumption that all learners have had the same experience and opportunities prior to evaluation which in most cases is not the actual situation (Naeini \& Duvall, 2012). Studies conducted on the comparison between dynamic and static 
assessment among children in a kindergarten have shown that the assessment method enables children to perceive learning process at the level of a visual motor as well as at symbolic levels (Pena et al., 2001). Furthermore, Skills mostly evaluated using dynamic assessment are associated with cultural, sociocultural as well as linguistic aspects of the learners. It has also been noted that the assessment enables learners to acquire problem-solving skills and apply these skills in solving various problems during learning (Naeini \& Duvall, 2012). On the other hand, many static tests have showed that learners are described in general terms, such as in terms of their relative position within their peer group rather than providing consistent descriptions of their learning processes or remedial learning strategies (Lantolf \& Poehner, 2005).

Mirzaei, Shakibaei, and Jafarpour (2016) have compared the efficiency of dynamic assessment and non-dynamic assessment in developing vocabulary knowledge. They have revealed in their mixed research that DA is more effective to maintain the depth of vocabulary knowledge. Moreover, the qualitative analysis of their study particularly the dialogic feedback sessions have manifested that DA could be used as a diagnostic means to help the teachers to identify what the learners actually know about each word and what they can reflect the support provided for them. Similarly, Miri et al. (2017) have shown in their study which is concerned with the difference between dynamic assessment and non-dynamic assessment that both types can be successful to assist how much learners understand the definite and indefinite articles in English; nevertheless, concurrent dynamic assessment is of a great value since it could better engage learners both verbally and bodily. Furthermore, Amerian and Mehri (2015) have investigated the impact of DA on gaining control over the past tense. They have found that students who have received interactionalist dynamic assessment show an apparent advancement at the end of the instructional sessions as well as obvious management to use the past tense in new situations.

In fact, the use of dynamic assessment methods outweighs static ones. Since they account for non-intellectual factors that can affect learner' cognitive performance such as intrinsic motivation, need for mastery anxiety, anger, tolerance, locus of control, and self-confidence which are just as important as "pure" cognitive factors in assessing learners' academic achievements (Pena et al., 2001), they are often recommended to be used more.

\section{Theoretical Background of Dynamic Assessment}

A number of theories including social development theory have been used to derive the dynamic assessment method in contrast to static method. Lev Vygotsky's theory of zone proximal development and Reuben Feuerstein's theory of mediated learning experience are considered inspirational theories to dynamic assessment to be proposed (Poehner, 2008). Vygotsky's theories of cognitive development offer profound insights into assessment in the language classroom by revealing hidden aspects of learners' abilities while answering questions through collaborative learning. Therefore, the analysis of zone of proximal development can be used to evaluate the ability of the student to learn from the interaction with a teacher or a more competent peer and this can help to predict their possible progress in the future whereas this can be described as difficult in traditional or non-dynamic assessment which can show only the already existent abilities of the students (Nazari, B. \& Mansouri, S., 2014). The distinction between a learner's "actual developmental level as determined by independent problem solving" or the higher level of "potential development as determined by problem-solving in adult guidance or in cooperation with more competent peers" was already described as the ZPD (Nazari \& Mansouri, 2014, p. 137).

According to Social Development Theory, social interaction is critical for cognitive development. Every function in the child's cultural development appears twice, first on social level, and eventually on the individual level; as it can be described between individuals (inter-psychological), and then within the child (intra-psychological). Indeed, the notion that the potential for cognitive development is dependent on the "zone of proximal development" which is a level of development achieved when learners participate in social behavior is the second component of Vygotsky's theory. Full social interaction is required for the ZPD to be fully utilized. To illustrate, teacher's guidance or peer collaboration will help learners to develop a wider range of skills than they could be capable of on their own. Besides, Vygotsky's theory has tried to explain consciousness as the result of socialization. While learning a language, first utterances with peers or teachers are intended to communicate, but once mastered they become internalized and allow inner communication to be processed. Strategies and rules to be used in solving particular problems can be assessed by static assessment whilst internalization of these strategies and rules and the transfer value to other problems with the same level of abstraction, novelty, and complexity can be successfully assessed by using methods of dynamic assessment (Nazari \& Mansouri, 2014).

Socio cultural theory is a key component of situated learning theory and can be accounted for as complement to Bandura's work on social learning. It has to be demonstrated that Vygotsky's views on cognitive development are intriguing to contrast with those of a constructivist of Bruner and a genetic of epistemologist Piaget. Thus, the 
purpose of approaching dynamic assessment is to supplement standardized testing, not as a replacement. It is portrayed as a general approach rather than a specific type of testing. In DA, varied criteria are extremely considered such as the degree of learning transfer, the amount and type of teaching needed, and pre-to-post teaching gains (Hidri, 2019).

Regarding mediated learning experience theory, Feuerstein (1998) stated that human beings are open rather than closed systems, thus their cognitive abilities can be developed in a variety of ways, depending on the presence and the quality of appropriate forms of interaction and instruction. To explain, mediated learning experience interactions are characterized as a process in which experienced adults or more knowledgeable mediators intervene between the learner and a set of stimuli, modifying the stimuli for the learner's development. In addition, Lidz and Gindis (2003) have argued that DA is an approach to understanding individual differences and their implications for instruction that require mediation within the assessment procedure. This can emphasize that the focus of most dynamic assessment procedures is on the process rather than on the product of learning. In other words, in DA the mediator seeks to improve learners' performance through modification of their activities which include various forms of interaction that focus on learner's behavior and receptivity to mediation (Lidz, 1991).

It is worth mentioning that the decision used to change criteria to help to predict cognitive performance of learners as well as the outcome of intervention is founded on the conviction that measures should be more closely linked to teaching processes that enhance information processing which is not the case of traditional methods of measurement. To elaborate, under circumstances where standardized tests yield low scores, DA has proven to be the most efficient in clinical experiences, when a learner comes from a low socioeconomic or different cultural linguistical background; when there are serious discrepancies between a learner's test scores and academic performance; when a learner shows some emotional disturbance, personality disorder, or learning disability; and when standardized tests hover around margins of adequacy in cognitive functioning (Poehner, 2008; Hidri, 2019).

DA has been found to confirm the distinction between cultural deprivation and cultural difference in some studies (Ebadi et al., 2018). Following Feuerstein, Tzuriel as they have distinguished between those who perform poorly as a result of cultural differences and those who have been deprived of cultural experiences. In this regard, DA approach is considered a solution not only because of its differential diagnostic value, but also because of its potential for prescriptive remediation of deficiencies and learning process enhancement. Significant positive correlations have been found between the level of difficulty of an item and the level of improvement on that item for certain DA measures, and DA post-teaching scores predict academic performance better than static scores. Indeed, many studies' findings have revealed serious doubt on the ability of static assessment scores to accurately represent the individual ability, particularly among low-functioning groups and to serve as indicators for future intervention and change (Ebadi et al., 2018).

\section{Technology in Language Assessment}

\subsection{Using Technology in Language Assessment}

As it has been proven that technology with its improvements has its radical impact on all the fields of our life, it has been demonstrated how much it can be beneficial to be utilized in the context of EFL learning. No educationalist would deny the importance of using new technologies to enhance the learning environment and the subject area of foreign languages is no exception (Blake, 2013). Using technology includes the use of systems such as computers and telecommunications to store, retrieve, and share data, as well as the use of the same technology to determine students' understanding of different subjects (Chapelle \& Voss, 2008).

Language assessment using technology which is known as computer-assisted language testing, has improved language testing among learners, with a focus on using technology to produce tests and process test-takers' linguistic responses. The application of computer adaptive testing for productivity increased the use of technology in language testing with the invention of automated test-takers' writing scores. This has progressed to include computer adaptive testing and a variety of language statistical techniques. Additionally, language processing approaches have also been used in the assessment of learner's spoken and written languages, as well as the assessment of results by corpus linguistics (Chapelle \& Voss, 2016).

For a long time, static assessment methods have been used to assess language. However, it has been observed that, with the current use of dynamic assessment methods to improve the process, technology can play a key role in assessing learners on a more realistic and system-oriented basis. Since its application through hardware, effective software, and the advantage of being able to reach out to a large number of learners, technology has been noted to improve language learning assessment (Chapelle \& Voss, 2016). According to various studies, the 
use of technologies in schools has been a huge success, with numerous advantages (Chapelle \& Voss, 2008). It has been used to outline exactly what learners should be taught and tested on, as well as the importance of technology in process of language assessment itself. To illustrate, many technologies have been recently developed and applied, including software, hardware, telecommunications, and analysis to be used in measuring the linguistic competencies and performance of language learners.

The use of technology in linguistics has flourished language assessment and made trainers' ability to gauge learner capacity simpler and quicker, according to studies that have been conducted to explore the differences between computers assisted language tests and other assessment methods such as static test methods (Jamieson, 2005). Language assessment will soon be possible through the use of high-tech solutions as well as strong software to allow language assessments as technology improves. It is worth noting, however, that authorizing language assessments through the use of technology may present significant challenges, as technological hardware and software evolve. This may be due to assessors' lack of understanding of the various potential technical influences on test results, as well as testers' lack of familiarity with technology in language testing.

While technology has increased the effectiveness of language assessment, a comparison of language teaching and learning is critical because it is the foundation for forming language assessment criteria. A psychometric approach has been used, in which reliable statistical data is obtained and used as data by computer programs to aid in the selection of relevant test questions when learners are taking their tests. Thus, language testers' efficacy had improved as a result of computer adaptive assessment test reporting. Moreover, language directors have confirmed that technology has provided them with the instruments they need for effective and accurate proficiency testing (Chapelle \& Voss, 2016).

Microcomputers in language assessment have been combined with a computer adaptive system to improve language assessment effectiveness. As a result, language experts have been urged to consider the use of technology when developing new tests in order to adopt the different ways that have been advanced through computer adaptive testing technology. These improvements include improved skill and placement testing effectiveness. Besides, they have addressed problems associated with the assessment of learners' performance (Tarighat \& Khodabakhsh, 2016).

It has to be displayed that the use of technology in language assessment has led test developers to rethink some of the constructs they test, such as multimedia listening comprehension testing. Prior to the use of computers in language tests, listening comprehension has been limited to the examiner's oral presentation which was either live or prerecorded in most cases. However, using computers in tests and assessments helps teachers to contextualize oral language with photographs with the possibility of allowing them to control their test-taking speed and request repetitions. Furthermore, innovative methods of evaluating spoken and written languages have been developed and utilized along with technological advancements as well as many challenges and constraints have been overcome by the help of technology. One of the main constraints, which was an over-reliance on selected-response items like multiple choices, has been removed. Language assessment technologies have contributed to develop the scoring system and the way learners constructed linguistic responses are assessed. This is an extremely significant improvement because it removes the use of multiple options, which has been shown to limit the ability of learners to be tested in terms of language learning. The use of technology to assess dialogic skills in speaking has been maintained by using concurrent applications that can fully manifest how students interact with speaking tests. Consequently, all these forms would benefit both spoken and written languages enhancement as well as increasing the effectiveness of language testing (Jamieson, 2005).

It should be distinctly considered that the use of technology has made language assessment validation simple and possible where corpus linguistics is of a great value. This entails interpreting scores based on a collection of texts produced by students or examiners. Likewise, test developers use this technology to define criteria linguistic features used by learners at various stages of development. Technical advancements in language testing and evaluation have been applied to social and political contexts, making technology more available and feasible for test developers, test takers, and test users (Tarighat \& Khodabakhsh, 2016).

\subsection{Using Social Media in Dynamic Assessment}

Social media as the widest form of using technology that are apparently embedded with our life has been the topic of varied studies to emphasize its effectiveness in foreign language learning. Drastic changes in the field of language education have taken place as a result of these studies. For instance, the roles of teachers and learners have been modified. As learners become more positive, teachers facilitate the interaction and promote using the foreign language in authentic tasks as Dalton (2009) has suggested in his research. Cacchione (2015) has argued that the solution for a good emotional management of the students is linking their academical content to 
experiences so that their positive emotions associated with these experiences become associated with the learning and that can be achieved by the use Mobile Learning functionalities like micro-blogging, she has added that the use of social media and mobile applications can contribute to create experiences of Situated Learning which is structurally based on the integration with the context, it is completely embedded in the dynamic flow of experience. Therefore, dynamic assessment is the most adequate method to be used to assess students in such experiences because it can be integrated into the learning process without interrupting and blocking it. However, it helps to promote and enhance the process of learning by becoming part of it.

Indeed, it has to be stated that the use of social media platforms has made the application of technology in language assessment easier and wider. As 80 percent of the world's population has access to the internet via social media. Video conferring has now become possible due to the use of various applications of social media, which encourages a practical method of evaluating students using a dynamic assessment method (Anderson \& Jiang, 2018). In order to assess learners' language understanding, a variety of social media platforms can be equipped in dynamic assessment such as Zoom, Facebook, LinkedIn, twitter, and WhatsApp which are just few examples.

Administrations of internet-based tests and other tests that could be administered via social media has been used in instructional strategies. Social media has improved interaction between instructors and learners, and this provides a fruitful opportunity for educators to use these platforms for assessing the linguistic performance of the learners. Therefore, dynamic Assessment through social media emphasizes the significance of interaction between the tester and the learner and creates diversified forms for this interaction. In addition, it has to be noted that the number of social media users has exploded, and as a result, educationalists should adopt this platform in order to reach out to a large number of learners (Lauchlan \& Carrigan, 2013).

Since Dynamic Assessment entails active teaching and learning between teachers and learners, social media can be an excellent platform to be exploited to fulfil this as it allows the learners and the teachers to communicate in the most possible naturalistic way (Hasson, 2017). Furthermore, using social media in dynamic assessment is completely advantageous as it provides learners with numerous chances to fully communicate with teachers in all areas where the teachers intend to measure the learner's linguistic ability and understanding.

Despite all these benefits of using social media in the dynamic assessment of language learning and how it maintains all the effects of dynamic assessment on language learners, it can be declared that a handful research has been conducted to delve into its impact and the best ways to be implemented in language testing and assessment. Cacchione (2015) has conducted an experimental study on the creativity of using twitter as a microblogging application on the dynamic assessment of foreign language learners at university. She has found that tweets have been created by the learners are extremely diverse and have showed a great variety of forms, content, and relationship with the context. Additionally, her study has assured the interactivity that social media can offer through the conversations between students and teachers which reinforces the mediation dynamic assessment relies on.

According to Cacchione, Dynamic Assessment is strongly related with a radically un-traditional teaching approach where teaching, learning, and assessment are integrated. Thus, promoting the establishment of a positive and relaxing environment, highly favorable for language learning in particular. She has concluded that the diversity and the originality of the tweets created by the students in the experiment often going beyond what has been proposed in the classroom and including multimedia contents, quotations of lyrics and poems, jokes and personal memories, confirm this potentiality and open more space to further exploitation of the tool where some remarks can be done regarding the role of innovation and creativity. Pedagogically, utilizing such applications can be related to MALL and it can booster the relationship between cognition memory and learning itself and with two key features of learning success: novelty and intensity (Cacchione, 2015).

In the same vein, Alemi, Miri, and Mozafarnezhad (2019) have studied the use of Telegram as an application of social media to improve dynamic assessment of the grammatical accuracy of EFL learners. The researchers have stated that despite such efforts in the actual context of the classroom, no studies have been conducted to implement dynamic assessment in the virtual world of some instant messaging applications such as Telegram, which has turned to be used by a considerable number of people. They have argued that the use of online group dynamic assessment can play a significant role in improving EFL learners' accuracy in different tasks. Moreover, they found that that online DA in the context of Telegram could assist students to make an evident progress in terms of writing accuracy. Besides, it has been shown that students' performance in online context surpasses theirs on the traditional context. They have suggested that the teachers need to run some parts of their classes such as writing in online context since the feedback given by the teacher or other peers can remain in the online 
context. To illustrate, using online social networks can help teachers not only to save more time but also to enhance the efficiency of feedback methods. Consequently, taking advantages of the findings to stimulate teachers and learners to benefit from social networks like Telegram is recommended (Alemi et al., 2019).

It has to be manifested that the impact of using social media in the dynamic assessment of the advancement of language learning needs to be debated in the Saudi EFL context. As a plenty of research has been done to investigate the massive uses of social media in language learning in general by a lot of Saudi researchers in different contexts, using these pivotal technological applications in the dynamic assessment of language learners should be empirically studied. Additionally, a further research is required to delve into the efficiency of assessing language learning through social media and how it can contribute to boost online learning which has evidenced its great significance in Saudi Arabia during the crisis of Corona. Furthermore, the various effects of using social media to evaluate the progress of EFL Saudi learners dynamically should be intensively researched.

\section{Conclusion}

To conclude, dynamic assessment as a method of incorporating teaching with assessment and providing language learners with the most authentic tasks to probe their learning has been evidenced as an extremely beneficial. Indeed, it has to be adopted not only as a method of assessment but also as a method of enhancing learning and teaching the foreign languages. Furthermore, exploiting social media to function dynamic assessment should be highly considered and investigated in various contexts as it could create precious opportunities to improve assessment of learners' capacities, teaching and mediational procedures, and creativity of providing corrective feedback for learners during the process of learning.

\section{References}

Ableeva, R. (2010). Dynamic assessment of listening comprehension in L2 French (Unpublished doctoral dissertation). The Pennsylvania State University, University Park, PA. Available at Penn State Libraries.

Alemi, M., Miri, M., \& Mozafarnezhad, A. (2019). Investigating the Effects of Online Concurrent Group Dynamic Assessment on Enhancing Grammatical Accuracy of EFL Learners. International Journal of Language Testing, 9(2), 29-43.

Anderson, M., \& Jiang, J. (2018). Teens, social media \& technology 2018. Pew Research Center, 31(2018), 1673-1689.

Baek, S. G., \& Kim, K. J. (2003). The effect of dynamic assessment based instruction on children's learning. Asia Pacific Education Review, 4(2), 189-198. https://doi.org/10.1007/BF03025361

Benjamin, L., \& Lomofsky, L. (2002). The effects of observation of dynamic and static assessment on teacher's perceptions of learners with low academic results. Journal of Cognitive Education and Psychology, 2(2), 97-118. ttps://doi.org/10.1891/194589502787383281

Blake, R. J. (2013). Brave new digital classroom: Technology and foreign language learning. Georgetown University Press.

Cacchione, A. (2015). Creative use of Twitter for Dynamic Assessment in Language Learning classroom at the university. Interaction Design and Architecture(s) Journal, 2,145-161.

Chapelle, C. A., \& Voss, E. (2008). Utilizing technology in language assessment. Encyclopedia of language and education, 7, 123-134. https://doi.org/10.1007/978-0-387-30424-3_172

Chapelle, C. A., \& Voss, E. (2016). 20 years of technology and language assessment in language learning \& technology. Language Learning \& Technology, 20(2), 116-128.

Cornfield, L. (2001). Report from the field: Mediated learning and structural cognitive modifiability as a methodology for psychotherapy. Journal of Cognitive Education and Psychology, 1(3), 294-302. https://doi.org/10.1891/1945-8959.1.3.294

Dalton, A. (2009). Teaching and learning through social networks. Teaching English, British Council.

Ebadi, S., Weisi, H., Monkaresi, H., \& Bahramlou, K. (2018). Exploring lexical inferencing as a vocabulary acquisition strategy through computerized dynamic assessment and static assessment. Computer Assisted Language Learning, 31(7), 790-817. https://doi.org/10.1080/09588221.2018.1451344

Falik, L. H. (2000). Mediated learning Experience and Counseling Process. In A. Kozulin \& Y. Rand (Eds.), Experience of Mediated Learning. An Impact of Feuerstein's Theory in Education and Psychology (pp. 309-324). Oxford: Elsevier. 
Feurstein, R., Rand, Y., \& Rynders, J. E. (1988). Don't accept me as I am. New York and London: Plenum. https://doi.org/10.1007/978-1-4899-6128-0

Gipps, C. (1994). Developments in educational assessment: what makes a good test? Assessment in Education: Principles, Policy \& Practice, 1(3), 283-292. https://doi.org/10.1080/0969594940010304

Hasson, N. (2017). The dynamic assessment of language learning. Routledge. https://doi.org/10.4324/9781315175423

Haywood, H. C., \& Lidz, C. S. (2006). Dynamic assessment in practice: Clinical and educational applications. Cambridge University Press. https://doi.org/10.1017/CBO9780511607516

Haywood, H. C., \& Tzuriel, D. (Eds.). (2013). Interactive assessment. Springer Science \& Business Media.

Hidri, S. (2019). Static vs. dynamic assessment of students' writing exams: a comparison of two assessment modes. International Multilingual Research Journal, 13(4), 239-256. https://doi.org/10.1080/19313152.2019.1606875

Jamieson, J. (2005). Trends in computer-based second language assessment. Annual Review of Applied Linguistics, 25, 228. https://doi.org/10.1017/s0267190505000127

Lauchlan, F., \& Carrigan, D. (2013). Improving learning through Dynamic Assessment: A practical classroom resource. London: Jessica Kingsley Publishers. https://doi.org/10.1080/08856257.2014.907985

Lidz, C. S. (1991). Practitioner's guide to dynamic assessment. Guilford Press. https://doi.org/10.4135/9781473957770.n2

Lidz, C. S., \& Gindis, B. (2003). Dynamic Assessment of the Evolving Cognitive. Vygotsky's educational theory in cultural context, 99. https://doi.org/10.1017/CBO9780511840975.007

Lussier, C. M., \& Swanson, H. L. (2005). Dynamic assessment: A selective synthesis of the experimental literature. In G. M. van der Aalsvoort, W. C. M. Resting \& A. J. J. M. Ruijssenaars (Eds.), Learning potential assessment and cognitive training: Actual research and perspectives in theory building and methodology (pp. 65-87). New York: Elsevier.

Malmeer, E., \& Zoghi, M. (2014). Dynamic Assessment of Grammar with Different Age Groups. Theory \& Practice in Language Studies, 4(8). https://doi.org/10.4304/tpls.4.8.1707-1713

Mehri, E., \& Amerian, M. (2015). Challenges to dynamic assessment in second language learning. Theory and Practice in Language Studies, 5(7), 1458-1466. https://doi.org/10.17507/tpls.0507.19

Mirzaei, A., Shakibei, L., \& Jafarpour, A. A. (2016). ZPD-based dynamic assessment and collaborative L2

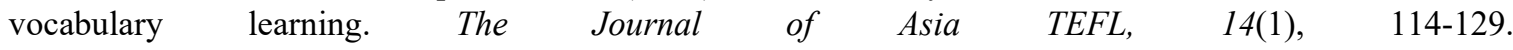
https://doi.org/10.18823/asiatefl.2017.14.1.8.114

Naeini, J., \& Duvall, E. (2012). Dynamic Assessment and the Impact on English Language Learners' Reading Comprehension Performance. Language Testing in Asia, 2, 22. https://doi.org/10.1186/2229-0443-2-2-22

Nazari, B., \& Mansouri, S. (2014). Dynamic assessment versus static assessment: A study of reading comprehension ability in Iranian EFL learners. Dil ve Dilbilimi Çalı̧̧maları Dergisi, 10(2). https://doi.org/10.7575/aiac.alls.v.5n.3p.191

Peña, E. D., Gillam, R. B., \& Bedore, L. M. (2014). Dynamic assessment of narrative ability in English accurately identifies language impairment in English language learners. Journal of Speech, Language, and Hearing Research, 57(6), 2208-2220. https://doi.org/10.1044/2014_JSLHR-L-13-0151

Peña, E., Iglesias, A., \& Lidz, C. S. (2001). Reducing test bias through dynamic assessment of children's word learning ability. https://doi.org/10.1044/1058-0360(2001/014)

Poehner, M. E. (2008). Dynamic assessment: A Vygotskian approach to understanding and promoting L2 development. In Educational Linguistics (pp. 1-197). Springer Science + Business Media B.V. https://doi.org/10.4324/9780203813850-8

Poehner, M. E., \& Lantolf, J. P. (2005). Dynamic assessment in the language classroom. Language Teaching Research, 9(3), 233-265. https://doi.org/10.1191/1362168805lr166oa

Rashidi, N., \& Bahadori Nejad, Z. (2018). An investigation into the effect of dynamic assessment on the EFL learners' process writing development. SAGE Open, 8(2). https://doi.org/10.1177/2158244018784643 
Tabatabaei, S., \& Bakhtiarvand, M. (2014). Application of Dynamic Assessment in Second and Foreign Language Teaching. International Journal for Teachers of English, 4(3), 1-14.

Tarighat, S., \& Khodabakhsh, S. (2016). Mobile-assisted language assessment: Assessing speaking. Computers in Human Behavior, 64, 409-413. https://doi.org/10.1016/j.chb.2016.07.014

Van Compernolle, R. A., \& Williams, L. (2012). Promoting sociolinguistic competence in the classroom zone of proximal development. Language Teaching Research, 16(1), 39-60. https://doi.org/10.1177/1362168811423340

Vygotsky, L. S. (1980). Mind in society: The development of higher psychological processes. Harvard university press. https://doi.org/10.2307/j.ctvjf9vz4

\section{Copyrights}

Copyright for this article is retained by the author(s), with first publication rights granted to the journal.

This is an open-access article distributed under the terms and conditions of the Creative Commons Attribution license (http://creativecommons.org/licenses/by/4.0/). 